\title{
The Influence of Debate on Chinese College Students' Critical Thinking Disposition: A Multiple Case Study Based on Paul-Elder Model of Critical Thinking
}

\author{
Yanan $\mathrm{Hu}$ \\ School of Languages and Cultures \\ Shanghai Normal University Tianhua College \\ Shanghai 201815 \\ 2362968937@qq.com
}

\begin{abstract}
In China, compared with the growing enthusiasm in debate among Chinese students, research in this field is relatively weak. Therefore, in order to gain an in-depth understanding of how forensic participation influence students' critical thinking, especially their intellectual disposition, I conducted this multiple case study based on Paul-Elder Model of Critical Thinking. My research question is "How does Chinese college students' critical thinking disposition change as a result of participating in debate?" After six month's observation on the debate team and three face-to-face interviews with each respondent, I found that forensic participation helps developing student's intellectual traits, which are indispensable to critical thinking skills. Moreover, forensic participation helps the students to get rid of ego-centric and socio-centric thinking, which paves the way for them to become real critical thinkers.
\end{abstract}

Keywords-Debate; Intellectual traits; Paul-Elder Model of Critical Thinking; Multiple case study

\section{INTRODUCTION}

The development of critical thinking skills is imperative for college students in China. Previous research has demonstrated the educational benefits and pedagogical function of forensics as a facilitator to critical thinking development for Chinese college students [1] [2] [3] [4]. Not only do many scholars acknowledge the importance of debate for critical thinking, but also the Chinese government stresses the necessity of developing innovative and critical thinking abilities in higher education [5]. However, the great enthusiasm for debate stands in sharp contrast to the limited research in the field [6]. In China, research in this field is still at a primary stage and there is a great need for in-depth qualitative analysis aimed at exploring students' development of critical thinking disposition. Therefore, I want to conduct a multiple case study to fill this gap and to provide more in-depth understanding in this field.

\section{CONCEPTUAL FRAMEWORK}

Considered as the guru in critical thinking, Paul has been highly recognized in the scholarly world [7]. Paul has been a great influence for other scholars who acknowledge his unique contribution to the conceptual understanding in this field [8] [9]

Focusing on the cross-disciplinary interpretation of critical thinking, his model emphasizes the transferability of critical thinking skills in all domains. In the following sections, I explain three major components of Paul-Elder model of critical thinking: elements of thought, standards and intellectual traits.

Elements of thought. Paul points out that, "the elements of thought are fundamental for thinking" [10]. These elements (purpose, questions at issue, information, interpretation and inference, concepts, assumptions, implications and consequences, point of view) are important for the substantive analysis of any problem (see Figure 1).

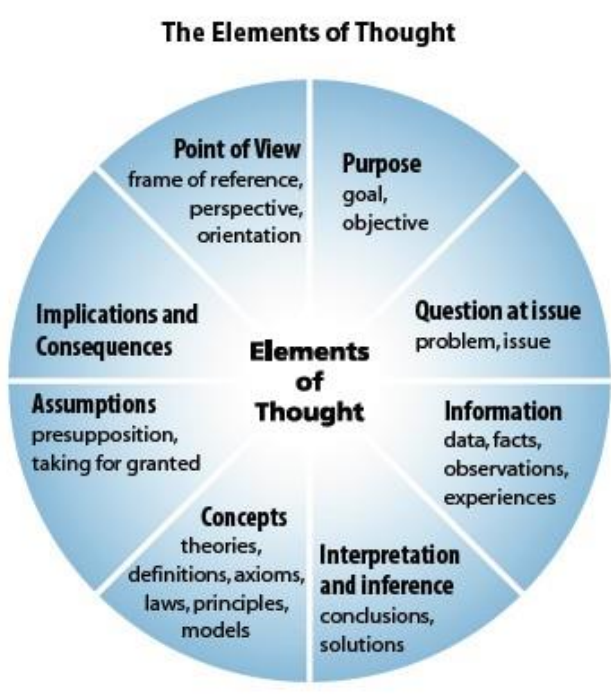

Fig. 1. Elements of Thought 
Paul and Elder summarize the reasoning process as follows: "You achieve some purpose from your own point of view, settle some problems, make some assumptions, collect some information, seek for some theory, provide some interpretations and offer some implications" [10]. Since these elements of thought represent analytical concepts, they can be applied in any context. Therefore, students can apply each element of thought according to the different context and "understand not only the influence of a separate element but also how they interact with each other to impact the whole" [10].

Standards. Like other scholars who focus on the standards and believe that adherence to criteria is of vital importance to conceptual understanding of critical thinking, Paul also attaches importance to the universal intellectual standards.

According to Paul and Elder, "students will apply these standards to reason in a more logical and fair manner" [10]. The standards include "clarity, accuracy, precision, relevance, depth, breath, logic, significance and fairness" [10].

When adopting the above standards, students can check if their reasoning is clear, accurate, precise and relevant to the topic discussed. One benefit of these standards is that since they are trans-disciplinary in nature, they can be applied in all domains of thought and students can use these criteria to motivate them to think deeply and in various courses. Another benefit of these standards is that they can help students to prevent egocentric thinking and socio-centric thinking. The former does not take other people's ideas into consideration and the latter one places his or her own culture above all others.

Intellectual traits. Intellectual traits are dispositions that characterize good qualities or virtues a critical thinker should possess. Paul summarizes the features of intellectual traits as follows. First, these traits or intellectual values, including intellectual humility, intellectual autonomy, intellectual integrity, intellectual courage, intellectual perseverance, confidence in reason, empathy and fair-mindedness (See figure 2), are interdependent and each can be best developed while the others are also gaining improvement. Second, these traits distinguish the narrow-minded, selfish thinker from the openmined thinker, for these traits focus on the ethical conduct and help to guide thinkers to develop a deep concern for others. As Linda Elder points out, "if we turn a blind eye to the cultivation of intellectual traits, we are vulnerable to suffer from intellectual arrogance, cowardice, narrow-mindedness and hypocrisy"[10]. Thus, Paul and Elder emphasize that the standards must be applied to the elements of thoughts and critical thinking abilities should develop with the intellectual traits so as to prevent selfish or egocentric thinking.

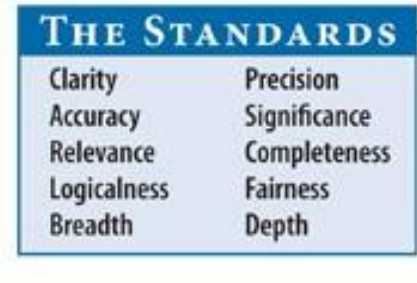

Must be applied to

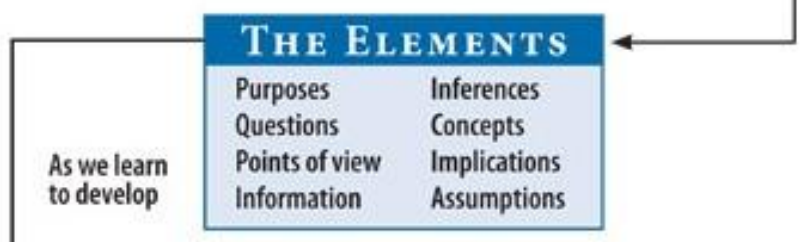

Fig. 2. Paul-Elder Model of Critical Thinking

Intellectual traits are difficult to develop, for people have a egocentricity and socio-centricity tendency to "believe what serves to justify their interest and validate their desires"[10].

Therefore, by applying these essential intellectual traits to the elements of thought, students will have the guidance to become not only a good thinker but also a responsible thinker. With these virtues in mind, students can "be more courageous to challenge the traditional thinking, more tolerant to others' ideas, more confident in reasoning and have greater control of their own thinking" [10].

\section{METHODOLOGY}

\section{A. Research question}

How does Chinese college students' critical thinking disposition change as a result of participating in debate?

\section{B. Respondent selection}

I used purposeful sampling as my respondent selection strategy. In purposeful sampling, "the researcher selects individuals and sites for study because they can purposefully inform an understanding of the research problem and central phenomenon" [11]. From Sun Rising forensic team, one of the famous debate team in China, I chose Dora, Helen and Sharon as my participants. All of them are regional or national champions and their rich experience in forensic participation later offered me a deep insight into this issue. 


\section{Data collection}

For the three debaters, my major qualitative data were three one-on-one interviews with the respondents and secondary interviews with their coach and teachers. In addition, I have also conducted some observations on their forensics training sections. Besides, I also collected some of their debate briefs, the judges' comments and the newspaper coverage on their participation in debate competitions. Online data included the official blog of this team, my e-mail correspondence with the students and information culled from their personal social networking sites. The operative details of my data collection procedure will be discussed in later sections.

\section{Analysis Procedures}

In order to gain an in-depth portrait of the cases, I built case descriptions for each respondent. For the analysis procedure, I applied the Paul-Elder Model of Critical Thinking to the findings. Last, I identified themes across cases.

As for the coding, I followed both Creswell's and Patton's suggestions on data coding, category grouping and theme finding procedure [11] [12]. First, I "create and organize files for data". Second, I read through all my data to get a general impression of the information. I used marginal notes to start my initial organizing and coding. After several readings of the text, I used different color pens to start my open coding. Each different color represents a different category and I wrote shorthand codes on the relevant places in the text.

Third, in order to identify categories, I looked for recurring regularities in the data. In the qualitative study and I constantly reviewed my categories to find the similarities and differences that exist within the interview among the three respondents. Then, I used categorical aggregation to find themes or patterns. After the systematic analysis of the coding from various data sources, the themes unfolded naturally and then I presented these themes to my readers and draw conclusions.

\section{RESULTS}

Intellectual traits, or intellectual dispositions characterize the attitudes and behaviors of the critical thinkers. Paul argues that these traits are the fundamental aim of critical thinking and education, for it distinguishes the selfish thinker from the openminded thinker. Each trait can maintain its independent character and at the same time work well with others. Paul argues that these dispositions can play a vital role in personal ethical development and helps one to get rid of the psychological obstacles, namely, egocentricity and sociocentricity. The former results from the selfish thinking that one's interests are superior to others and not acknowledging the limits of his or her thought. The later comes from the prejudices of one's culture and placing their culture and society above all others.

\section{A. Dora and intellectual traits}

During my interviews with Dora, she told me that debate brought her not only the change of her thinking, but the improvement of her intellectual disposition as well. And the latter, to some extent, could have a more direct impact on her personal growth. The most distinct characteristics

I could identify in her case are intellectual integrity, intellectual empathy and perseverance.

Intellectual integrity. This intellectual trait is very difficult to develop due to people's tendency to judge and evaluate things according to their own standards. Therefore, admitting one's discrepancies and inconsistency in one's thought could become fairly hard if one firmly upholds his or her previous opinions. Dora recalled that, at first, she could easily get humiliated if she was challenged and beaten by others during debate competitions. But after some time, she began to appreciate and learn from the strong points of her opponents and acknowledge the weakness in her thought. To her, failure or even losing face in front of the audience was not that important. What matters is the process of the learning and it is through these defeats that she finally found her problem and made a great progress.

Intellectual empathy. It refers to "have the consciousness to place oneself in others' position for the sake of others" [13]. Through the discussion and debating of the various social issues, Dora became more aware of the world that is different from her, of the people that are not as fortunate as her and of the many social problems that do not have an easy solution. She begins to show more sympathy toward the poor and more understanding of the people who are different from her. Dora no longer only cares for herself and thinks only from her own perspective. Instead, she is more willing to take the responsibility to help to solve these social problems and can take a more inclusive attitude to accept other people's life styles.

Intellectual perseverance. Debate is challenging, both mentally and physically. For students like Dora, they struggle to find a balance between their own academic study and their forensic participation. According to the coach, many seniors left not because of their loss of passion in this activity, but of the heavy workload that it requires. For Dora, things are different; what strike the coach most are her perseverance and her great motivation. She might not be the smartest person in the debate team, but she is definitely the most hardworking student. Whenever the coach assigns the homework for the next training, she always makes the fullest preparation.

She often contacts the coach and other teachers for the latest news in the debate circle. She treats debate very seriously and even if it requires her great amount of time and energy, she will not complain, for she really likes debate. 


\section{B. Helen and intellectual traits}

According to the stages of critical thinking development, critical thinkers should go through the steps from "unreflective thinkers, challenged thinkers, beginning thinkers, practicing thinkers, advanced thinkers to accomplished thinkers" [13]. It is hard to define what kind of thinker Helen is at the current level, but she is certainly trying her best to become a confident and courageous person who is able to analyze, synthesize and evaluate the things that are happening around her.

Confidence in reason. It refers to "People learn to form their rational arguments, to draw reasonable conclusions and to think in a logic way with the help of constant encouragement" [13]. Before Helen took part in debate, she was an unsuccessful public speaker. After her talent was discovered by her judge and she received systematic training in forensics, she became a confident debater who excels at logic analysis. The encouragement from the judge and years of training transformed Helen to a successful debater. Although sometimes, she could be a bit aggressive during the tournaments and according to her coach, she can be even better if she slows down a bit, but her overall performance is stunning. In her opinion, female debaters should not be overshadowed by their counterparts and she thinks that females need more confidence to compete with the boys.

Intellectual courage. Besides being more confident, Helen is now more courageous to voice her own opinions. Intellectual courage refers to "Not passively accepting what we have learned and being true to our own thinking" [13]. In Helen's opinion, to be a real critical thinker, one must have his or her own thinking without blindly following others' viewpoints. She told me that all the strong critical thinkers she has met are from the debating circle and it is through these debaters that she has come to realize the importance of expressing one's own voice.

Throughout her middle school and high school years, Helen, just like other students, regarded teachers as the primary source of information and she respected them a lot. It never occurred to her that teachers could also make mistakes or that she could challenge them even if she found something wrong. After she entered college and joined the debate team, she was more courageous to express her own opinions and accept only those things that make sense to her. That is not to say that she has more pride in herself or does not respect the teachers as she used to. On the other hand, she takes a more serious attitude toward knowledge and can critically analyze various pieces of information without blindly following others' opinions.

\section{Sharon and intellectual traits}

Interestingly enough, the confident Sharon who could stun the audience by her excellent language abilities used to be a very shy person. She attributes most of her success to debate, for it gives her confidence in reason and at the same time, develops her intellectual humility.

Confidence in reason. This intellectual trait requires thinkers to have the belief that they can think independently and draw their own conclusions. Back in the high school, Sharon admitted that she was a very shy person and would instantly turn red if she was asked to stand in front of a group of people. But after she participated in the debate club in the college, she gradually got rid of her pervious shyness. The weekly mock debate and numerous local and national tournaments have built up her ability to speak confidently. She is now more at ease to present her arguments and to make her own decisions. When I asked her what is the first thing that pops up in her mind relating to her gains in debate, she replied that, Debate has given me guts, to question the things that I see, it also gave me confidence, confidence to speak in front of many people, confidence to succeed in the future and confidence to do things that I like.

Intellectual humility. It implies the thinker "should not pretend to know what one actually does not know. On the other hand, one should honestly acknowledge his or her own limits in their thinking" [13]. Being a language major, Sharon clearly understands her strength lies in her eloquence and her weakest point is the limit of knowledge. She honestly admitted that the heaviest blow of her forensic participation was during one international debate tournament where the topic was relating to the Middle East. Not having enough knowledge on the topic, Sharon suffered a crushing defeat. It was after this round that she realized that her current reading was not enough and she had to work even harder to catch up with her counterparts from other countries.

Another sign of her intellectual humility is that she classified herself with old-fashioned debaters who are more humble and less aggressive. She told me that during her time as a middle and high school student, being humble was regarded as a good merit. However, after she taught the debate course and gave training to the young debaters, she found out that the young people might have different opinions toward humbleness. For some of them, debate offered a chance to show off their talents and wisdom. Even if they do not know the motions very well, they will still act very confidently and sometimes pretend to know more what they actually do not know. Sharon would rather be the humble student who is honest about her shortcomings, but at the same time is eager to learn. 


\section{CONCLUSIONS}

The purpose of my research is to gain an in-depth understanding of how forensic participation influences students' critical thinking disposition at the college level in China. Three respondents were interviewed and observed.

My previous chapters provided the description of three participants' intellectual dispositions. While there exist similarities in terms of their intellectual traits still remain. Based on my interviews with and observations of Dora, Helen and Sharon, I gained a deeper understanding of their critical thinking disposition. And my findings are as follows.

\section{A. Finding One}

Forensic participation helps developing students' intellectual traits, which are indispensable to critical thinking skills.

Intellectual traits are considered as an indispensable part to the development of critical thinking skills [13]. The transition from an unreflective thinker to an accomplished thinker not only requires the development of thinking skills but also the cultivation of intellectual traits. However, previous research only mentioned that to become a well- cultivated thinker, one has to acquire both intellectual skills and traits without making clear the relationship between them. I found that the intellectual virtues are closely related to intellectual skills, for the former can to some extent facilitate the development in the latter.

My participants developed intellectual traits. The most distinct characteristics I could identify in Dora's case are intellectual integrity, intellectual empathy and perseverance.

Helen, developed confidence in reason and intellectual courage and Sharon, intellectual humility and confidence in reason. These traits not only make them well-cultivated critical thinkers, which distinguish them from the selfish and narrowminded ones, but also facilitate the development of their critical thinking skills. For example, confidence in reason requires "the thinkers to have the confidence to see things from rational viewpoints, to think logically and to draw reasonable conclusion" [13]. Therefore, students can be more confident to make their own analysis and judgment of the issue, thus improve their analyzing and evaluating skills.

Intellectual courage states that critical thinkers should not uncritically accept what they have learned and sometimes absurd ideas can be justified. Undoubtedly, when one develops this trait, he or she will not blindly follow others' viewpoints. Rather, when reading materials, he or she will raise questions to doubt the ideas and thus improve critical reading skills.

Further, intellectual traits can help students become more socially responsible. Scholars like Mezuk (2010) have argued that forensic participation has a positive effect on students' civic empowerment. In other words, it can provide a good platform for students to become good citizens [14].

My multiple case studies echo this finding. Debaters like Dora have developed intellectual empathy, which put themselves in the place of others and to reason for the benefit of others. When Dora debates a topic on health welfare, she will think of those people who are not fortunate to enjoy this benefit. For her, winning the debate takes a backseat. What really matters is solving this problem through debate. This transition is significant, for it shows that Chinese young debaters are getting more concerned with social and economic problems. They are debating for others' sake and they shoulder more social responsibilities in debate.

\section{B. Finding Two}

Forensic participation helps the students to get rid of egocentric and socio-centric thinking.

Many researchers believe that one of the biggest contributions of Paul and Elder's model of critical thinking is its emphasis on the importance of getting rid of ego-centic and socio-centric thinking. According to Paul, the reason why critical thinking is needed results from a thinking tendency to distort the meaning to fit self interest and an inability to see the limitation of personal viewpoint.

My respondents admitted that forensic participation has broken many stereotypes for them and constantly encouraged them to think in various perspectives, which might sometimes go against their previous beliefs. For them, the most obvious improvement is that they are trying to get rid of their innate egocentrism, innate wish fulfillment and innate self-validation. First, in terms of innate egocentrism, my participants will not blindly follow others' opinions. For example, Helen has the confidence to challenge authority and can find logical fault in a famous professor's lecture. Second, they have tried to move out of their comfort zone and force themselves to think in a totally different manner. For instance, Dora honestly admitted that pushing herself to debate for the idea she used to disagree with is a demanding job. But now, she enjoys this process and can think from various perspectives. Third, as to challenging the beliefs that one has long upheld, my participants think this is one of the most difficult parts of debate. For example, when debating the issues on the historical events, Helen used to find it quite unpleasant to debate for the idea that she is strongly against. But after debating with many debaters from other countries, she finally learns to jump out of her own comfort zone and to embrace many different opinions.

Socio-centric thinking is another problem relating to our biased and distorted thinking. It refers to placing one's own culture above all others and purposefully turns a blind eye to those who think differently. Being born in a county with a history of 5000 years, my respondents are unconsciously influenced by the deep-rooted thinking pattern in China. For instance, at the beginning year of their forensic participation, they might be a bit embarrassed when they debated the topics such as gay marriage and legalization of prostitution, for Chinese people rarely talk about these issues in public. After they took part in national and international debate competitions, they are now more willing to accept different ideas and show more understanding of the people with different living style. 


\section{RECOMMENDATION TO FURTHER STUDY}

I found that in China, female debaters play a very important role in competitive debate competitions. Unlike America where females can be greatly overshadowed by their male counterparts in number, girls in China seem to be more active. The reasons can be two-fold. First, currently Chinese education system which emphasizes on reciting and memorizing favors girls and girls can perform better than boys in their academic study. Second, when Chinese university wants to take part in the international competitions, they will normally select students with good English abilities and therefore, females, who are usually skilled in linguistic abilities, have more chances to be selected.

Therefore, in my future study, I want to dig deeply to the issue of female debaters in China and might conduct another qualitative study on the long-term effect of forensics, especially in terms of the intellectual disposition on their future life.

\section{REFERENCE}

[1] Liu,D.H.(2005). Daxuesheng yingyu xiezuo zhong pipanxin siwei nengli yanjiu[The study in the critical thinking in writing course for college students]. Foreign Language Teaching and Research Press, (3):46-51.

[2] Peng, Q.L.(2002). Sibian yu chuanxin-kouyu ketang shang de yanjiang.speech and debate in oral English course[Critical thinking and innovation-A s study on the use of speech and forensics in oral English course].Foreign Language World,78(2):39-44.

[3] Wang,A.J.(2005). Yingyu bianlun shi quanmian tigao xuesheng yingyu nengli de youxiao tujin[English debate is an effective tool to improve students' English ability]. The Border Economy and Culture, 17(5):111113.

[4] Zhang,J.(2012). Yingyu Zhuangye xuesheng pipanxing siwei de peiyang-Yi yuedu ke zhong de yingyu bianlun wei li. [The Cultivation of critical thinking abilities of English majors-A case study of using debate in reading course]. Journal of Zhangzhou Normal University Philosophy and Social Studies.

[5] Li R.F. (2002). The cultivation of students' creativity and critical thinking. Foreign Language Education. 23(5).

[6] Liu,H.,\&Jin,L.M.(2012).Yingyu bianlun yu daxuesheng pipanxin siwei fazhan de shizheng yanjiu[An empirical study on English debate and college students' critical thinking development]. Foreign Language Teaching and Research, 266(5):24-28.

[7] Hale, E. (2008). Project demonstrating excellence: A critical analysis of Richard Paul's substantive trans-disciplinary conception of critical thinking (Doctoral dissertation). Retrieved fromhttp://www.criticalthitiking.org/files/Hale PDE Final.pdf.

[8] Fasko,D. (2003). Critical thinking:origins, historical development, future directions. In D.Fasko (Ed.), Critical thinking and reasoning:Current Research Theory and Practice,3-18.

[9] Hitchcock,D.(2002). Bertrand Russell and critical thinking. Inquiry: Critical Thinking Across the Disciplines, 20 (2),3-50.

[10] Paul, R. \& Eder, L. (2006d). The miniature guide to critical thinking concepts and Tools (4th ed.). Dillon Beach, CA: Foundation for Critical Thinking.

[11] Creswell ,J.W.(2007). Qualitative inquiry and research design: choosing among five approaches(3rd Ed.). Thousand Oaks:Sage.

[12] Patton,M.Q.(2002). Qualitative evaluation and research methods(3rd Ed.).Thousand Oaks: Sage.

[13] Paul, R., \& Elder, L. (2009c). A glossary of critical thinking terms and concepts. Dillion Beach, CA: Foundation for Critical Thinking.

[14] Mezuk, B. (2009). Urban debate and high school educational outcomes for African-American males; The case of the Chicago debate league: The Journal of Negro Education, 78 (3), 290-304. 